\title{
ROLE OF THE RUBISCO SMALL SUBUNIT
}

\author{
Final Report
}

for Period May 1, 1997 - April 30, 2000

( $\$ 279,000$ total funding)

Robert J. Spreitzer

University of Nebraska

Lincoln, Nebraska 68588-0664

October 4, 2000

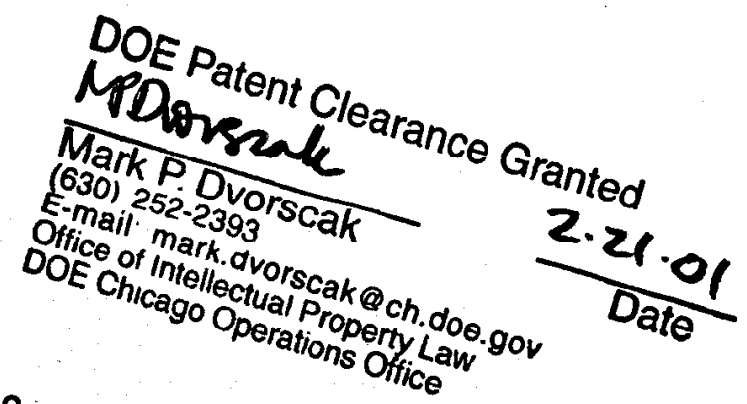

Prepared for

THE U.S. DEPARTMENT OF ENERGY

AWARD NO. DE-FG02-97ER20261 
DISCLAIMER

This report was prepared as an account of work sponsored by an agency of the United States Government. Neither the United States Government nor any agency thereof, nor any of their employees, makes any warranty, express or implied, or assumes any legal liability or responsibility for the accuracy, completeness, or usefulness of any information, apparatus, product, or process disclosed, or represents that its use would not infringe privately owned rights. Reference herein to any specific commercial product, process, or service by trade name, trademark, manufacturer, or otherwise does not necessarily constitute or imply its endorsement, recom. mendation, or favoring by the United States Government or any agency thereof. The views and opinions of authors expressed herein do not necessarily state or reflect those of the United States Government or any agency thereof. 


\section{DISCLAIMER}

Portions of this document may be illegible in electronic image products. Images are produced from the best available original document. 


\section{INTRODUCTION}

$\mathrm{CO}_{2}$ and $\mathrm{O}_{2}$ are mutually competitive at the active site of ribulose-1,5-bisphosphate (RuBP) carboxylase/oxygenase (Rubisco). Whereas carboxylation of RuBP is the rate limiting step of photosynthetic $\mathrm{CO}_{2}$ fixation, oxygenation of RuBP ultimately leads to the loss of fixed carbon via the photorespiratory pathway. The $\mathrm{CO}_{2} / \mathrm{O}_{2}$ specificity $(\Omega)$ of Rubisco is determined by the $\mathrm{V}_{\max }$ of carboxylation and oxygenation $\left(\mathrm{V}_{\mathrm{c}}\right.$ and $\mathrm{V}_{\mathrm{o}}$, respectively) and the $\mathrm{K}_{\mathrm{m}}$ for $\mathrm{CO}_{2}$ and $\mathrm{O}_{2}\left(\mathrm{~K}_{\mathrm{c}}\right.$ and $\mathrm{K}_{\mathrm{o}}$, respectively) such that $\Omega=V_{c} K_{d} / V_{0} K_{c}$ (Laing et al. 1974). Directed mutagenesis of the active-site large subunit has deepened our understanding of the Rubisco catalytic mechanisms (reviewed by Hartman and Harpel 1994; Cleland et al. 1998; Spreitzer 1998), and classical genetic methods have identified large-subunit regions that control $\mathrm{CO}_{2} / \mathrm{O}_{2}$ specificity (reviewed by Spreitzer 1993, 1998). We now have a much better idea of the prospects and limitations for improving the enzyme in favor of carboxylation (Chen and Spreitzer 1992; reviewed by Spreitzer 1999). Because of its pivotal role in both plant productivity and the balance of our planet's atmospheric $\mathrm{CO}_{2}$ concentration (reviewed by Tolbert 1997), further study of this enzyme is warranted. However, Rubisco contains two subunits, each present in eight copies. In plants and green algae, the well-studied 55-kD large subunit is coded by the chloroplast $r b c L$ gene, but the $15-\mathrm{kD}$ small subunit is coded by a family of nuclear $R b c S$ genes. The role of the small subunit in Rubisco structure or catalytic efficiency is not known. Only recently have we succeeded in eliminating the two $R b c S$ genes in the green alga Chlamydomonas reinhardtii (Khrebtukova and Spreitzer 1996). The RbcS deletion mutant lacks photosynthesis, but it can be maintained with acetate-supplemented medium in darkness. This mutant can also be rescued on minimal medium in the light by transformation with either the RbcSI or $R b c S 2$ gene (Khrebtukova and Spreitzer 1996). It is now possible to address questions about the structure-function relationships of the eukaryotic small subunit.

\section{SPECIFIC AIMS OF THE CURRENT PROJECT}

There are three specific aims in the current project: (1) Alanine scanning mutagenesis is being used to dissect the importance of the $\beta A / \beta B$ loop, a feature unique to the eukaryotic small subunit. (2) Random mutagenesis is being used to identify additional residues or regions of the small subunit that are important for holoenzyme assembly and function. (3) Attempts are being made to express foreign small subunits in Chlamydomonas to examine the contribution of small subunits to holoenzyme assembly, catalytic efficiency, and $\mathrm{CO}_{2} / \mathrm{O}_{2}$ specificity.

\section{ACCOMPUSHMENTS AND WORK IN PROGRESS}

\section{Directed Mutagenesis}

It was previously reported that differential expression of $R b c S$ family members in fern might be correlated with differences in Rubisco carboxylase specific activity (Eilenberg et al. 1991), but detailed kinetic analysis of fern Rubisco has not been done (Eilenberg et al. 1998). Because the two small subunits of Chlamydomonas differ by four residues (T22S, A47S, T128S, and F132W), and may be differentially expressed in darkness (Goldschmidt-Clermont and Rahire 1986), we constructed and analyzed an RbcSI/RbcS2 chimera (Khrebtukova and Spreitzer 1996). Small subunits expressed by the $R b c S 1, R b c S 2$, or chimeric gene (following transformation into the $R b c S$ deletion mutant) produced functional holoenzymes in light or darkness, but RbCS1 appeared to produce a slightly higher transformation frequency and level of holoenzyme (Khrebtukova and Spreitzer 1996). More recently, when we compared holoenzymes purified from wild type, an $R b c S 1$ transformant, an $R b c S 2$ transformant, and the chimeric $R b c S$ transformant, no significant differences were found in $V_{c}, K_{c} / K_{o}$, or holoenzyme thermal stability. Thus, both small subunits appear to be equivalent, further indicating that the differences in small-subunit sequence play no 
essential role in Rubisco function. We have used $R b c S I$ for directed mutagenesis studies due to its higher transformation frequency and presumed level of expression.

\section{ALANINE SCANNING MUTAGENESIS}

Several directed mutagenesis studies of the small subunit have been performed with cyanobacterial Rubisco expressed in Escherichia coli (reviewed by Spreitzer 1993, 1999). Changes in conserved residues dispersed within primary structure either have little effect, decrease holoenzyme stability, or decrease carboxylation catalytic efficiency. No clear picture of the role of the small subunit has emerged from these studies, and it has been difficult to define functionallysignificant interactions between large and small subunits.

The small subunit of cyanobacterial Rubisco lacks 12 residues of a 22-residue loop (between B-strands A and B) that is characteristic of plant small subunits (Fig. 1) (Newman and Gutteridge 1993; Schreuder et al. 1993; Andersson 1996). This $\beta A / \beta B$ loop extends between and over the ends of two large subunits from the bottom side of the $\alpha / \beta$-barrel active site, and also interacts with the same loop of a neighboring small subunit (Andersson 1996). Wasmann et al. (1989) inserted the pea $R b c S$ loop region (residues 45 through 65 ) into cyanobacterial $R b c S$ (replacing residues 45 through 53), performed in vitro transcription and translation of the chimeric gene, and checked for holoenzyme assembly after import of the small subunit into pea chloroplasts. The chimeric small subunit was now able to assemble with pea large subunits within the chloroplast. Although it would appear that the loop is essential for assembly, subsequent directed mutagenesis and chloroplast import studies identified only one residue (Arg-53) that was critical to this process (Flachmann and Bohnert 1992; Adam 1995). The other substitutions (E54R, H55A, P59A, D63G, D63L, and Y66A; Flachmann and Bohnert 1992) may have affected Rubisco function, but not enough holoenzyme can be assembled by transport into isolated chloroplasts to permit biochemical analysis.

Spinach
Tobacco
Pea
Maize
Chlamydomonas
Synechococcus
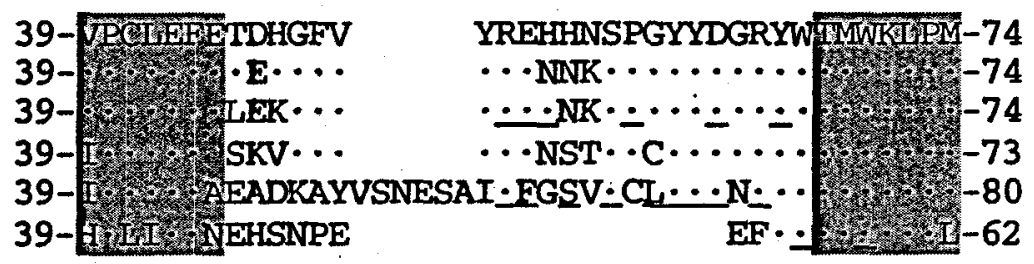

Figure 1. Comparison of small-subunit sequences in the $\beta A / \beta B$ loop region. Assignment of secondary structure ( $\beta$-strands $A$ and $B$ in gray) is based on the $X$-ray crystal structure of spinach Rublsco (Andersson 1996). Residues identical with those of the spinach small-subunit sequence are marked ( $)$. Residues investigated via directed mutagenesis of pea, Chlamydomonas, and cyanobacterial small subunits are underlined in the respective sequences (Noordouw et al. 1987; Fitchen et al. 1990; Lee et al. 1991; Flachmann and Bohnert 1992).

Our primary focus has been placed on examining the significance of the $\beta \mathrm{A} / \mathrm{\beta B}-\mathrm{loop}$ residues that are conserved between Chlamydomonas and land plants, but that differ or are absent from the loop of the cyanobacterial small-subunit (i.e., Chlamydomonas Arg-59, Ser-64, Tyr-67, Tyr-68, Asp-69, and Arg-71) (Fig. 1). Although most of these residues and others have now been replaced via directed mutagenesis and transformation of Chlamydomonas, only two (F60A and R71A) fail to restore photosynthesis to the $R b c S$ deletion mutant (Table I). In particular, Tyr-67, Tyr-68, and Asp-69 are highly conserved residues (Fig. 1), but they are clearly not essential for holoenzyme function or assembly (Table I). We doubt that the $\beta A / \beta B$ loop is an "assembly domain" that actively facilitates holoenzyme assembly (Flachmann and Bohnert 1992). Further biochemical analysis of the mutant enzymes may reveal the true significance of this region with respect to Rubisco function. Preliminary results indicate that $\beta A / \beta B-l o o p$ substitutions can influence carboxylation efficiency, $\mathrm{CO}_{2} \mathrm{O}_{2}$ specificity, and holoenzyme stability (Table I). 
Table I. Directed mutations in the Rubisco small subunit of Chlamydomonas. Mutations were made in the RbcSt gene, which was then transformed into a strain that lacks both RbcS genes (Khrebtukova and Spreitzer 1996). The $\mathrm{N}_{2} / \mathrm{O}_{2}$ ratio is the ratio of RuBP carboxylase activities determined at limiting $\mathrm{CO}_{2}$ under $100 \% \mathrm{~N}_{2}$ and $100 \% \mathrm{O}_{2}$. The $\mathrm{N}_{2} / \mathrm{O}_{2}$ ratio is comparable to $\mathrm{K}_{0} / \mathrm{K}_{0}$ (Chen et al. 1988). ND, not determined.

\begin{tabular}{|c|c|c|c|}
\hline $\begin{array}{l}\text { Amino-acid } \\
\text { substitution }\end{array}$ & Base change & $\begin{array}{l}\text { Transformation } \\
\text { frequency }\end{array}$ & Biochemical result \\
\hline $\begin{array}{l}\text { R59A } \\
\text { R59E } \\
\text { F60A } \\
\text { S62A } \\
\text { S64A } \\
\text { L66F } \\
\text { L66G } \\
\text { Y67A } \\
\text { Y68A } \\
\text { D69A } \\
\text { R71A } \\
\text { F132UAA }\end{array}$ & $\begin{array}{l}C G C \rightarrow G C C \\
C G C \rightarrow G G \\
T T C \rightarrow G C C \\
A G C \rightarrow G C C \\
T C T \rightarrow G C C \\
C T G \rightarrow T C \\
C T G \rightarrow G C \\
T A C \rightarrow G C C \\
T A C \rightarrow G C C \\
\text { GAC } \rightarrow \text { GCC } \\
C G C \rightarrow \text { GCC } \\
\text { TTC } \rightarrow \text { TAA }\end{array}$ & $\begin{array}{c}1.4 \times 10^{-6} \\
1.7 \times 10^{-6} \\
0\left(\text { per } 8 \times 10^{7}\right) \\
1.0 \times 10^{-5} \\
N 0 \\
5.0 \times 10^{-7} \\
5.0 \times 10^{-6} \\
5.0 \times 10^{-7} \\
1.3 \times 10^{-5} \\
6.5 \times 10^{-6} \\
0\left(\text { per } 8 \times 10^{7}\right) \\
\left.2.5 \times 10^{-8}\right)\end{array}$ & $\begin{array}{c}\downarrow \text { thermal stability } \\
\downarrow k_{\text {cat, }} \downarrow \text { holoenzyme, } \downarrow \mathrm{N}_{2} / \mathrm{O}_{2} \text { ratio } \\
\text { no photosynthesis } \\
\downarrow k_{\text {cat }} \\
\mathrm{ND} \\
\downarrow k_{\text {cat }}, \downarrow \text { thermal stability, } \downarrow \mathrm{N}_{2} / \mathrm{O}_{2} \text { ratio } \\
\text { wild-type characteristics } \\
\downarrow k_{\text {cat }} \\
\mathrm{ND} \\
\mathrm{ND} \\
\text { no photosynthesis } \\
\downarrow k_{\text {cat, }} \downarrow \text { thermal stability }\end{array}$ \\
\hline
\end{tabular}

\section{ARG-59 IS NOT ESSENTIAL}

In previous studies of pea small subunits transported into isolated chloroplasts (Flachmann and Bohnert 1992; Adam 1995), an R53E substitution was found to block holoenzyme assembly. This observation led Flachmann and Bohnert (1992) to conclude that the highly conserved Arg residue was essential for assembly. When the homologous residue in the Chlamydomonas small subunit (Fig. 1, Arg-59) was changed to Ala in the current project, we found that this mutant small subunit restored photosynthesis in our $R b c S$ deletion strain (Table I). Although the mutant Rubisco has some associated thermal instability in vitro (Fig. 2), Arg-59 is clearly not essential for assembly.

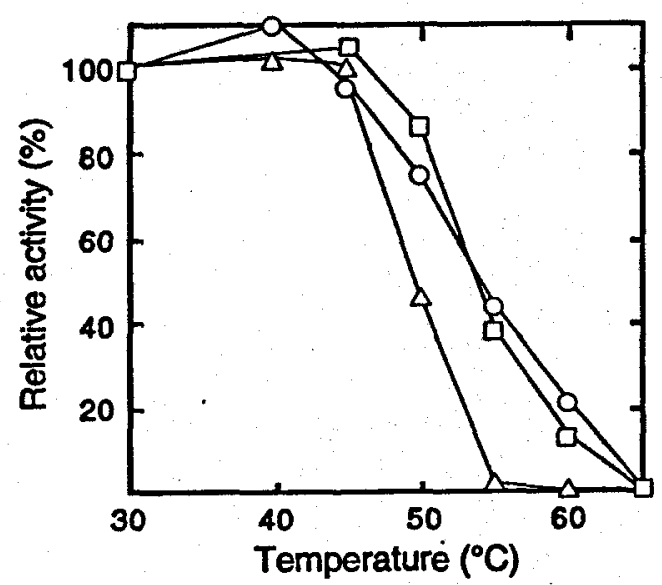

Figure 2. Thermal inactivation of purified Rubisco from wild type (O), RbcS1-wt (D), and mutant RbcS1-R59A ( $\triangle$ ). Purified Rubisco $\left(0.1-0.4 \mathrm{mg} \mathrm{ml}^{-1}\right)$ in $10 \mathrm{mM} \mathrm{NaHCO}$, $10 \mathrm{mM} \mathrm{MgCl}, 1 \mathrm{mM}$ DTT, and $50 \mathrm{mM}$ Bicine, $\mathrm{pH}$ 8.0, was incubated at each temperature for $10 \mathrm{~min}$. The samples were then cooled on ice, and RuBP carboxylase activity was assayed at $25^{\circ} \mathrm{C}$. Activities for each enzyme were normalized against the level of activity measured after the $30^{\circ} \mathrm{C}$ incubation. The RbcS1-wt strain was obtained by transforming the RbcS deletion mutant with the wild-type RbcS1 gene (i. e., This strain lacks RbcS2, as does the RbcS1-R59A strain).

Because one could argue that Arg-59 has a different function in Chlamydomonas Rubisco than in pea Rubisco (Fig. 1), we also created an R59E substitution. Once again, photosynthesis- 
competent transformants were recovered (Table I). However, in this case, the R59E mutant cells have a greatly-reduced level of Rubisco holoenzyme and grow exceptionally slowly, indicating that the presence of Glu at residue 59 is, in fact, detrimental to Rubisco assembly or stability. In other words, Arg-59 is not essential for assembly, but a negatively charged residue at this position appears to disrupt holoenzyme stability. Whereas R59A Rubisco has apparently normal kinetic constants, the $\mathrm{R} 59 \mathrm{E}$ enzyme has a reduced $\mathrm{k}_{\text {cat }}$ and reduced $\mathrm{N}_{2} / \mathrm{O}_{2}$ ratio (Table II). Thus, the smallsubunit $\beta A / \beta B$ loop can contribute to the catalytic efficiency of the distant large-subunit active site. Further study via directed mutagenesis and transformation in Chlamydomonas will allow this region to be dissected in detail.

Table II. RuBP carboxylase activity of Rubisco purified from wild type and RbcS1 directed mutants. Wild-type Rubisco contains two different small subunits (encoded by $R b c S 1$ and RbcS2 genes), but transformants contain only the RbcS1 gene.

\begin{tabular}{|c|c|c|c|c|}
\hline \multirow[t]{2}{*}{ Strain } & \multicolumn{3}{|c|}{$\begin{array}{l}\text { Carboxylase activity at } 25^{\circ} \mathrm{C} \\
\left(\mu \mathrm{mol} \mathrm{CO}_{2} \mathrm{~h}^{-1} \mathrm{mg} \text { Rubisco }\right.\end{array}$} & \multirow{2}{*}{$\begin{array}{c}\mathrm{N}_{2} / \mathrm{O}_{2} \text { ratio } \\
\text { (A/B) }\end{array}$} \\
\hline & $\begin{array}{l}100 \% \mathrm{~N}_{2} \\
9.86 \mathrm{mM} \\
\mathrm{NaHCO}_{3}\end{array}$ & $\begin{array}{l}\text { (A) } 100 \% \mathrm{~N}_{2} \\
0.53 \mathrm{mM} \\
\mathrm{NaHCO}_{3}\end{array}$ & $\begin{array}{l}\text { (B) } 100 \% \mathrm{O}_{2} \\
0.53 \mathrm{mM} \\
\mathrm{NaHCO}_{3}\end{array}$ & \\
\hline Wild type & 83.2 & 18.8 & 6.2 & 3.0 \\
\hline Transformant RbcS1-wt & 89.5 & 16.7 & 6.0 & 2.8 \\
\hline Transformant RbcS1-R59A & 81.8 & 16.3 & 5.5 & 3.0 \\
\hline Transformant RbcS1-R59E & 6.8 & 1.5 & 0.6 & 2.5 \\
\hline
\end{tabular}

\section{LEU-66 SPECIFIC INTERACTIONS}

We have also been investigating the $\beta A / \beta B$ loop in a different way. Some years ago, a Chlamydomonas chloroplast mutant was recovered by genetic screening, named $68-4 \mathrm{PP}$, that has a wild-type phenotype at $25^{\circ} \mathrm{C}$, but lacks Rubisco holoenzyme and requires acetate for growth at $35^{\circ} \mathrm{C}$ (Chen et al. 1988). When Rubisco was purified from $25^{\circ} \mathrm{C}$-grown cells, the mutant enzyme was found to have a decreased $V_{c}$, increased $\mathrm{K}_{0} / \mathrm{K}_{\mathrm{c}}$, and a $13 \%$ decrease in $\Omega$. Further studies showed that the mutant Rubisco is unstable at $35^{\circ} \mathrm{C}$ in vivo or in vitro (Chen et al. 1988, 1993). All of these altered enzyme properties arise from an $r b c L$ mutation that causes an L290F substitution in large-subunit $\beta$-strand 5, far from the active site at the bottom of the $\alpha / \beta$-barrel (Chen et al. 1988). More recently, photosynthesis-competent revertants were recovered from mutant 68-4PP (L290F) that arise from second-site mutations in $r b c L$ (Hong and Spreitzer 1997). Either an A222T substitution in $\alpha$-helix 2 or a V262L substitution below $\beta$-strand 4 (Hong and Spreitzer 1997) improves the thermal stability of the original mutant Rubisco and increases its $\Omega$ to the wild-type value (Hong and Spreitzer 1997). The "long distance" interactions between residue 290 and residues 222 and 262 are particularly interesting because all three residues are in Van der Waals contact with small-subunit residues in the $\beta A / \beta B$ loop (residues Pro-59, Gly-60, and Tyr-61 of spinach) (Fig. 3) (Andersson 1996). Now that it is possible to perform directed mutagenesis and transformation of the Chlamydomonas small subunit, the significance of these comparable residues can be studied (residues Cys-65, Leu-66, and Tyr-67 in Chlamydomonas, see Fig. 1). We have created an L66F substitution in the small subunit that should mimic the effect of the L290F substitution in the large subunit (Fig. 3). This L66F small-subunit mutant has the same temperature-conditional phenotype as the L290F large-subunit mutant (Chen et al. 1988), and both mutant enzymes display similar thermal instability in vitro (Chen et al. 1993). Preliminary biochemical analysis further indicates that the L66F and L290F enzymes have catalytic properties 
zred in similar ways (Chen et al. 1988, 199 993). Because land plants and some green algae $\checkmark$ at residue 66 (e. g., Fig. 1), we also crea reated an L66G substitution. The L66G mutant similar to the wild-type enzyme, indicating ing that is increased size of residue 66, not identity, that is responsible for the moar Codified properties of the L66F mutant enzyme. nteraction at the large/small-subunit interr resis-competent revertants of mutant $\mathrm{L} 66 \mathrm{~F} \ldots \mathrm{j}$ at $35^{\circ} \mathrm{C}$ to further explore this site.
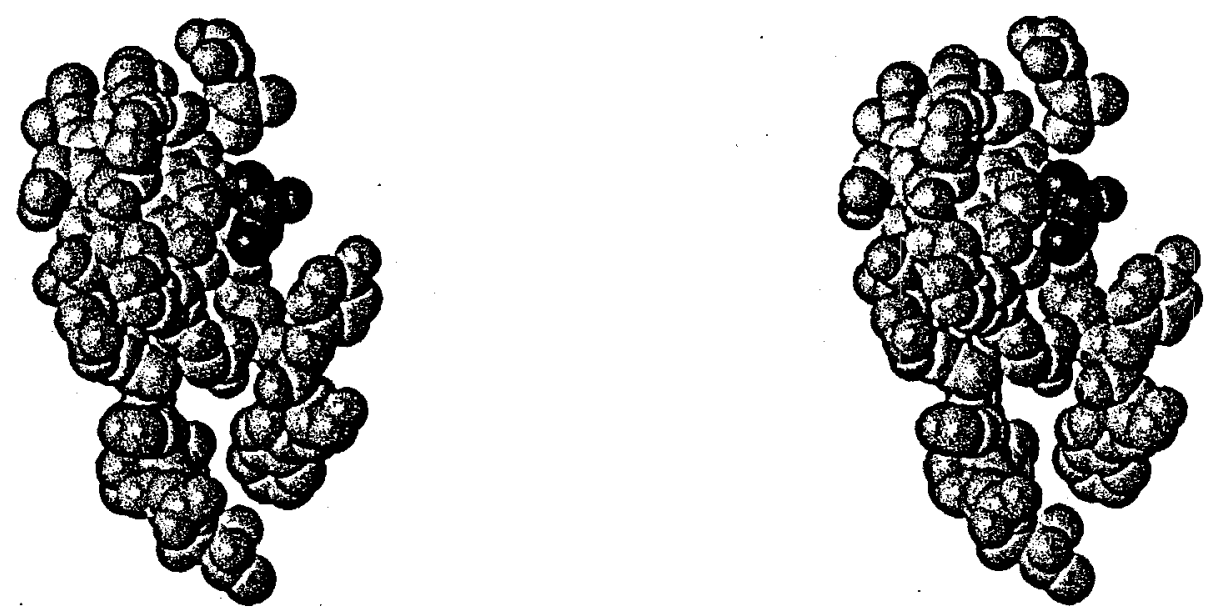

Figure 3. Stereo image of the spinach $\beta A=B A / B B$ loop (residues $46-67$ in green) (Andersson 1996). Interactions between th the Rubisco large and small subunits of Chlamydomonas that may influence car catalysis are illustrated. An L290F substitution (pink) at the bottom of the lar aarge-subunit $\alpha / \beta$ barrel (Chen et al. 1988) is complemented by a V262L substitu stitution (light blue) in the same large subunit or by an A222T substitution (dark blue) in a neighboring large subunit (Hong and Spreitzer 1997). Although =n these large-subunit residues are relatively far from each other, all are in _.......... in close contact with small-subunit residues. Large-subunit residues 222 Chlamydomonas and spinach Rubisco. $T$ The spinach small subunit contains Gly at residue 60 (red). but Chlam the Chlamydomonas small subunit also contan mains six additional residues (Fig. 1) that would reside between Val-51 and Tyr__.... Tyr-52 (both in yellow) of the spinach small subunit.

\section{C-TERMINAL TRL —RUNCATION}

bisco enzymes from eukaryotic red and b brown algae have been found to have $\Omega$ values ver than those of land-plant enzymes (e. g ieca $\Omega=110$, Galdieria partita $\Omega=230$ : g., Chlamydomonas $\Omega=60$, spinach $\Omega=80$, $I$ an attempt to understand the structural _ al basis for these differences, the X-ray crystal uas recently been solved for Rubisco from: Iom the thermophilic red alga Galdieria partita let al. 1999). This structure shows that the onger than that of spinach, folds back on $\longrightarrow$ itself and interacts with the $\mathrm{N}$-terminal side of $100 p$ (Fig. 3). The Galdieria BA/BB loop, 1 D. like that of the cyanobacterium Synechococcus acks the extra residues that are characteris ristic of green plants and algae. Sugawara et al. oposed that the small-subunit C-terminar_-nal extension may play a role in an enhanced ability and elevated $\Omega$ value of Galdieria n extended C-terminus, 11 residues longe guer than that of the spinach small subunit. By ; directed mutagenesis and transformation__ - on, we have introduced a stop codon that would length of the small subunit by 9 residues ues. Surprisingly, this F132UAA mutant strain tosynthetic competence (Table $\mathrm{I}$. Althou nough its $\mathrm{V}_{\mathrm{c}}$ is reduced by $56 \%$ relative to the $\mathrm{V}_{\mathrm{c}}$ Id-type enzyme, it has a normal $\mathrm{N}_{2} / \mathrm{O}_{2} \mathrm{r}$ ratio. Thus, this C-terminal extension is not 
essential for holoenzyme function or assembly. However, the F132UAA mutant enzyme displays significant thermal instability in vitro (Fig. 4), supporting the idea that the C-terminus plays a role in holoenzyme stability. Based on the Galdieria structure, we suspect that the C-terminus of the Chlamydomonas small subunit interacts with the extra six residues of its $\beta A / \beta B$ loop (Fig. 3).

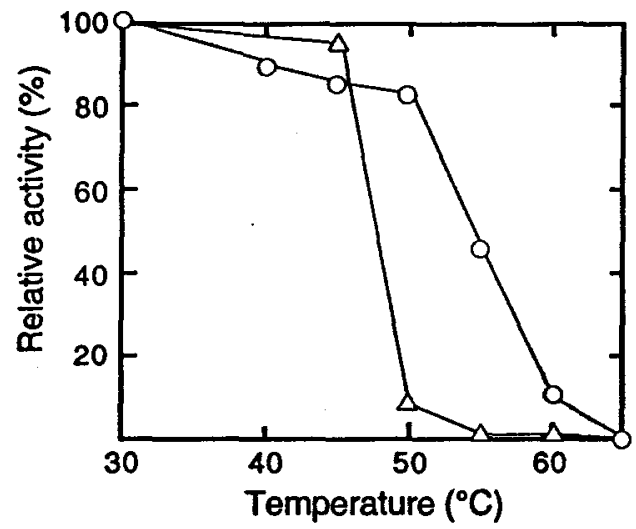

Figure 4. Thermal inactivation of purified Rubisco from wild type (O) and mutant RbcS1-F132UAA $(\triangle)$. Purified Rubisco $\left(0.1-0.4 \mathrm{mg} \mathrm{ml}^{-1}\right.$ ) in $10 \mathrm{mM} \mathrm{NaHCO}_{3}, 10 \mathrm{mM}$ $\mathrm{MgCl}_{2}, 1 \mathrm{mM} \mathrm{DTT}$, and $50 \mathrm{mM}$ Bicine, $\mathrm{pH}$ 8.0, was incubated at each temperature for $10 \mathrm{~min}$. The samples were then cooled on ice, and RuBP carboxylase activity was assayed at $25^{\circ} \mathrm{C}$. Activities for each enzyme were normalized against the level of activity measured after the $30^{\circ} \mathrm{C}$ incubation.

\section{Random Mutagenesis}

Random genetic screening and selection in Chlamydomonas have proven to be quite useful for identifying functionally-significant regions of the Rubisco large subunit (reviewed by Spreitzer 1993, 1998). The importance of such regions could not have been predicted by simply examining the existing crystal structures. Although $r b c L$ mutants were recovered at random, the identified amino-acid substitutions are not distributed randomly. Only the most deleterious (and important) substitutions are recovered, and, by selecting for second-site suppressors, specific interactions within tertiary and quaternary structure are identified (e. g., Thow et al. 1994; Spreitzer et al. 1995; Hong and Spreitzer 1997). RbcS mutants have not been recovered in Chlamydomonas by screening for photosynthesis-deficient, acetate-requiring mutants. Because there are two $R b c S$ genes, and either one is sufficient for photosynthetic growth (Khrebtukova and Spreitzer 1996), the probability of getting a deleterious point mutation in both genes simultaneously is vanishingly small (reviewed by Spreitzer 1993). Now that we have a Chlamydomonas strain that lacks both $R b c S$ genes (Khrebtukova and Spreitzer 1996), the application of in vivo genetic methods is possible.

\section{XL-1 RED AND TEMPERATURE-CONDITIONAL MUTANTS}

With respect to the second specific aim of the current project, random mutagenesis of $R b c S$ in the DNA-repair-deficient XI-1 Red $E$. coli strain has been found to give rise to temperatureconditional, photosynthesis-deficient strains when transformed into the Chlamydomonas $R b c S$ deletion strain. However, none of these mutants has yet been found to arise from a mutation in $R b c S$. When grown with acetate at the nonpermissive temperature of $35^{\circ} \mathrm{C}$, all of the mutant strains retain substantial levels of RuBP carboxylase activity. Because DNA integrates into the nucleus by nonhomologous recombination (Kindle 1990), we anticipated that the transforming DNA might produce nonspecific temperature-conditional mutants by disrupting other genes. We also expect that temperature-conditional $R b c S$ mutants will be rare (reviewed by Spreitzer 1993). Thus, it is still necessary to screen more colonies to assess the utility of this method. Even one temperatureconditional $R b c S$ mutant could be extremely valuable for identifying important regions of the small subunit (e. g., Spreitzer 1998).

\section{SMALL-SUBUNIT SUPPRESSION}

We have made an interesting discovery via genetic selection that has become a focus for further study. As apparent from the discussion above (see LEU-66 SPECIFIC INTERACTIONS, page 5), 
it took a long time to recover second-site rbcL suppressors (A222T and V262L) of the 68-4PP (L290F) rbcL mutant (Chen et al. 1988; Hong and Spreitzer 1997). The reason for this is that most photosynthesis-competent revertants of the temperature-conditional 68-4PP mutant arise from mutations in nuclear genes (Chen et al. 1990, 1993; Hong and Spreitzer 1997). Detailed genetic and biochemical analysis of one of these suppressors indicated that it acted posttranslationally to restore the low $\Omega$ value and thermal instability of 68-4PP (L290F) mutant Rubisco, but this nuclear suppressor mutation did not reside in either of the two $R b c S$ genes (Chen et al. 1990, 1993; Gotor et al. 1994). Recent genetic analysis has indicated that there are two distinct nuclear genes that can suppress the 68-4PP (L290F) rbcL mutation. Now that we have a better understanding of the structural interactions near the small-subunit $\beta A / \beta B$ loop (Hong and Spreitzer 1997; see LEU-66 SPECIFIC INTERACTIONS, page 5), we decided to screen alleles of the second nuclear-suppressor gene for mutations in $R b c S$. By PCR amplifying and sequencing DNA in the small-subunit $\beta \mathrm{A} / \beta \mathrm{B}-$ loop region (Fig. 1), we found that either an N54S or A57V substitution in the RbcS2 small subunit can complement the L290F substitution. Of the three revertant strains analyzed, one contained the $R b c S 2-N 54 S$ mutation and two contained the RbcS2-A57V mutation. These small-subunit substitutions increase the amount of Rubisco in $35^{\circ} \mathrm{C}$-grown cells to the wild-type level. A comparison of Rubisco enzymes purified from $25^{\circ} \mathrm{C}$-grown cells also indicated that the $R b c S$ mutations improve catalysis of the original 68-4PP (L290F) mutant enzyme by increasing its $\Omega$ value to that of wild-type Rubisco (Table III). This is an exciting finding because we now have evidence that the small-subunit $\beta \mathrm{A} / \beta \mathrm{B}$-loop region can, in fact, influence Rubisco $\Omega$.

Table III. RuBP carboxylase activity and $\mathrm{CO}_{2} / \mathrm{O}_{2}$ specificity $(\Omega)$ of Rubisco purified from the temperature-conditional 68-4PP mutant and its photosynthesis-competent revertants R116-1B and R116-10C. The $\mathrm{N}_{2} / \mathrm{O}_{2}$ ratio is comparable to $\mathrm{K}_{0} \mathrm{~K}_{0}$ (Chen et al. 1988). $\Omega$ values are the average of three separate enzyme preparations $\pm S D$ as determined with the $\left[{ }^{3} \mathrm{H}\right] \mathrm{RuBP} / \mathrm{NaH}^{14} \mathrm{CO}_{3}$ duallabeling assay (Jordan and Ogren 1981a; Spreitzer et al. 1982).

\begin{tabular}{|c|c|c|c|c|c|}
\hline \multirow[t]{2}{*}{ Strain } & \multicolumn{3}{|c|}{$\begin{array}{l}\text { Carboxylase activity at } 25^{\circ} \mathrm{C} \\
\left(\mu \mathrm{mol} \mathrm{CO}_{2} \mathrm{~h}^{-1} \mathrm{mg} \mathrm{Rubisco}{ }^{-1}\right)\end{array}$} & \multirow{2}{*}{$\begin{array}{c}\mathrm{N}_{2} / \mathrm{O}_{2} \text { ratio } \\
\text { (ABB) }\end{array}$} & \multirow{2}{*}{$\begin{array}{c}\Omega \\
\left(N_{0} K_{0} N_{0} K_{c}\right)\end{array}$} \\
\hline & $\begin{array}{l}100 \% \mathrm{~N}_{2} \\
9.86 \mathrm{mM} \\
\mathrm{NaHCO}\end{array}$ & $\begin{array}{l}\text { (A) } 100 \% \mathrm{~N}_{2} \\
0.53 \mathrm{mM} \\
\mathrm{NaHCO}_{3}\end{array}$ & $\begin{array}{l}\text { (B) } 100 \% \mathrm{O}_{2} \\
0.53 \mathrm{mM} \\
\mathrm{NaHCO}_{3}\end{array}$ & & \\
\hline Wild type & 65.2 & 11.2 & 3.7 & 3.0 & $60 \pm 1$ \\
\hline $\begin{array}{l}\text { Mutant 68-4PP } \\
\text { (BCL-L290F) }\end{array}$ & 19.9 & 2.9 & 1.2 & 2.4 & $54 \pm 1$ \\
\hline $\begin{array}{l}\text { Revertant R116-1B } \\
\text { ('bcL-L290F, RbcS2-N54S) }\end{array}$ & 44.9 & 6.1 & 2.2 & 2.8 & $60 \pm 3$ \\
\hline $\begin{array}{l}\text { Revertant R116-10C } \\
\text { (rbcL-L290F, RbCS2-A5TV) }\end{array}$ & 41.6 & 11.6 & 4.7 & 2.5 & $58 \pm 1$ \\
\hline
\end{tabular}

Genetic analysis of the R116-1B and R116-10C revertants, which contain the RbcS2-N54S and $R b c S 2$-A57V suppressor mutations, respectively, confirmed that the suppressors were inherited in a Mendelian pattern and have similar map distances (Table IV). After recovering $m t$ revertants from these crosses, backcrosses were performed to obtain progeny that lacked the original 68-4PP $r b c L$ mutation but retained the $R b c S 2$ suppressor mutation. In the absence of the $r b c L$ mutation, both suppressors were found to have wild-type (photosynthesis-competent) phenotypes. Strains that contain an $R b c S 2$ suppressor mutation are, in fact, heterogeneous for wild-type $R b c S 1$ and mutant RbcS2 small subunits. It is also interesting that the small-subunit N54S and A57V 
substitutions occur in the region of the $\beta \mathrm{A} / \mathrm{BB}$ loop that is six residues longer than the land-plant small-subunit $\beta A / \beta B$ loop (Figs. 1 and 3 ). We suspect that this inserted region is relatively far from both the large-subunit L290F substitution and the large-subunit residues that suppress it (A222T and V262L) (Hong and Spreitzer 1997) (Fig. 3).

Table IV. Genetic analysis of photosynthesis-competent R116-1B and R116-10C revertants of the temperature-conditional, photosynthesis-deficient 68-4PP mutant ( $\mathrm{B}$ CL-L290F).

\begin{tabular}{|c|c|c|c|c|c|}
\hline \multirow[t]{2}{*}{ Test cross } & & \multicolumn{3}{|c|}{$\begin{array}{l}\text { Tetrads } \\
\left(\text { score ac-p } f^{a}\right.\end{array}$} & \multirow{2}{*}{$\begin{array}{c}\text { Map } \\
\text { distance }^{\circ} \\
(X 100)\end{array}$} \\
\hline & & PD & NPD & $T$ & \\
\hline $\begin{array}{c}\text { (revertant R116-1B) } \\
\text { (rel-L290F, RbcS2-N54S, }+m t^{+} \times\end{array}$ & $\begin{array}{l}+,+, \rho f-2, m t \\
\text { (wild type) }\end{array}$ & 10 & 10 & 13 & 20 \\
\hline$\underset{\text { (revertant R116-10C) }}{\text { bcL-L290F, } R b c S 2-A 57 V, m t^{+} \times}$ & $\begin{array}{l}+,+, p f-2, m t \\
\text { (wild type) }\end{array}$ & 5 & 5 & 4 & 14 \\
\hline
\end{tabular}

All progeny receive the temperature-conditional chloroplast bcL-L290F mutation, but only two in a tetrad receive the nuclear RbcS2 suppressor mutation. In the absence of the suppressor, progeny lack photosynthesis at $35^{\circ} \mathrm{C}$ and require acetate (aC) for growth. Segregation was scored relative to the centromere-linked paralyzed flagella $(p)$ marker, which allows parental-ditype (PD), nonparental-ditype (NPD), and tetratype (T) tetrads to be defined. Distances (\% recombination) between the RbcS2 suppressors and their centromeres were calculated as $0.5 \mathrm{~T} /(\mathrm{PD}+\mathrm{NPD}+\mathrm{T})$.

DNA sequencing and restriction-enzyme analysis have been used to verify that $R b c S I$ has a wild-type sequence and that the $R b c S 2$ mutations are genetically linked with the suppressor phenotypes (e. g., see Fig. V). This work has also allowed the identification and recovery of strains that contain the $R b c S 2$ suppressor mutations but lack the original rbcL-L290F mutation (e. g., backcross progeny in Fig. V, lanes 9 and 10).

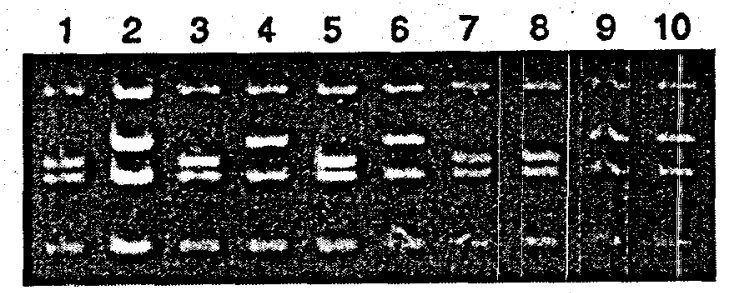

Figure V. Segregation of the RbcS2-A5TV suppressor mutation in reciprocal crosses. DNA was purified, and a 818-bp RbcS2 sequence was amplified by PCR. The PCR product was digested with Haelll and separated on a $3.5 \%$ agarose gel. The mutation eliminates a Haelll site, increasing the size of a 189-bp fragment to $210 \mathrm{bp}$. Lane 1, wild type; lane 2, revertant R116-10C (RbCS2-A5T, HCL-L290F); lanes 3-6, progeny from the cross R116-10C $\mathrm{mt}^{+} \mathrm{X}$ wildtype mt (progeny 3 and 5 had temperatureconditional, acetate-requiring phenotypes): lanes 7-10, progeny from the cross wild-type $m t^{+} \times R 116-10 C m t^{-}$(progeny 7-10 had wildtype phenotypes).

Because we have a strain that lacks both $R b c S$ genes (Khrebtukova and Spreitzer 1996), we have recently succeeded in transforming each of the $R b c S 2$ suppressor genes into Chlamydomonas in the absence of $R b c S 1$. If the suppressors improve the $\mathrm{V}_{c}$ and $\Omega$ of mutant $r b c L-L 290 \mathrm{~F}$ Rubisco, perhaps they will improve the wild-type enzyme. However, the RbcS2-N54S and RbcS2-A57V 
strains were recovered at a substantially lower transformation frequency $\left(2.5 \times 10^{-7}\right)$ than that for the wild-type $R b c S 2$ gene $\left(3.4 \times 10^{-6}\right)$, indicating that the homogeneous $R b c S 2-\mathrm{N} 54 S$ and $R b c S 2-$ A57V enzymes may be compromised in function or stability. By employing the [ $\left.{ }^{3} \mathrm{H}\right] \mathrm{RuBP} /$ $\mathrm{NaH}^{14} \mathrm{CO}_{3}$ dual-labeling assay (Jordán and Ogren 1981a), we have recently found that the $R b c S 2$ mutant enzymes have wild-type $\Omega$ values. Further kinetic analysis of the mutant enzymes is in progress. Regardless of the outcome, the discovery of these small-subunit substitutions will help guide future directed-mutagenesis studies of the $\beta A / \beta B$ loop.

\section{X-Ray Crystallography}

In a separate but related project, we are also making progress towards solving the X-ray crystal structure of Chlamydomonas Rubisco (Yen et al. 1998). Once this structure is available, it will become easier to ask questions about the large/small-subunit interface.

\section{Expression of Foreign Small Subunits}

The kinetic constants and $\mathrm{CO}_{2} / \mathrm{O}_{2}$ specificities differ among Rubisco enzymes from phylogenetically diverse species (Jordan and Ogren 1981b). To determine whether these differences may arise from differences in the small subunit, we have tried to complement the photosynthesis deficiency of our $R b c S$ deletion mutant with $R b c S$ genes from land plants. A few attempts with genomic clones proved unsuccessful, and we assumed that differences in introns and transit peptides may prevent expression of mature plant small subunits in Chlamydomonas. As a first step for eliminating these potential problems, we used directed mutagenesis to construct a gene in which the mature small-subunit coding region of the Chlamydomonas $R b c S I$ gene is replaced exactly by the mature small-subunit coding region of Chlamydomonas RbcS2 cDNA (Goldschmidt-Clermont and Rahire 1986). In other words, this new gene has wild-type 5' and 3' genomic flanking sequences and encodes the transit peptide, but it lacks the three introns that are characteristic of the Chlamydomonas RbcS genes (Goldschmidt-Clermont and Rahire 1986). The objective was to exploit engineered $X \mathrm{maI}$ and $\mathrm{XbaI}$ restriction sites for the routine, but precise, exchange of foreign $R b c S \mathrm{cDNA}$ in place of the mature protein coding region of Chlamydomonas $R b c S 1$. However, initial attempts at transforming the $R b c S$ deletion mutant with the Chlamydomonas $R b c S 2$ cDNA construct failed. Attempts with spinach $R b c S$ cDNA (Martin et al. 1996) and the cyanobacterial gene (Kleman et al. 1996) precisely replacing the Chlamydomonas mature small-subunit coding region also proved unsuccessful. To determine that our constructions were error free, we replaced the Chlamydomonas $R b c S 2 \mathrm{cDNA}$ sequence with the missing genomic sequence and observed transformation at the usual frequency.

Only recently have we succeeded in obtaining several Chlamydomonas RbcS2 cDNA transformants. This was accomplished by providing a long expression time after transformation to allow for the accumulation of Rubisco to maximal levels prior to selection (e. g., Spreitzer and Chastain 1987). However, the transformation frequency may be too low for the recovery of foreign $R b c S$ cDNA transformants, which we assume will be expressing Rubisco at lower levels or in compromised conditions. Other approaches may be necessary for expressing foreign small subunits in Chlamydomonas. Lumbreras et al. (1998) have recently found that introns 1 and 2 of Chlamydomonas $R b c S 2$ can increase the transformation frequency and level of mRNA for a bacterial gene expressed in Chlamydomonas. However, when we eliminated only intron 3 during the engineered replacement of the longer $\beta \mathrm{A} / \beta \mathrm{BB}-$ loop region of Chlamydomonas $R b c S 1$ with the shorter $\beta A / \beta B$ region of spinach $R b c S$, no photosynthesis-competent transformants were obtained. Either the longer $\beta A / \beta B$ loop is required for assembly or function of Chlamydomonas Rubisco, or intron 3 also plays a significant role in small-subunit expression. 


\section{PUBLICATIONS ACKNOWLEDGING THE AWARD}

Szot, J. C. and R. J. Spreitzer (1998) Alanine scanning mutagenesis of the Rubisco small subunit in Chlamydomonas. In Plant Biology 98: Final Program and Abstract Supplement. American Society of Plant Physiologists, Rockville, pp. 142 (Abstract).

Spreitzer, R. J. (1998) Genetic engineering of Rubisco. In The Molecular Biology of Chloroplasts and Mitochondria in Chlamydomonas, eds. J. D. Rochaix, M. GoldschmidtClermont and S. Merchant. Kluwer Academic Publishers, Dordrecht, pp. 515-527.

Spreitzer, R. J. (1999) Questions about the complexity of chloroplast Rubisco. Photosynth. Res. 60: $29-42$.

Du, Y., S. Hong and R. J. Spreitzer (1999) Small-subunit suppressors of a Rubisco large-subunit mutation. In Plant Biology '99: Final Program and Abstract Supplement. American Society of Plant Physiologists, Rockville, pp. 165 (Abstract).

Szot, J. C., M. G. Esquivel and R. J. Spreitzer (1999) Mutations in the Rubisco small subunit affect holoenzyme stability and catalysis. In Plant Biology '99: Final Program and Abstract Supplement. American Society of Plant Physiologists, Rockville, pp. 168 (Abstract).

Spreitzer, R. J., M. G. Esquivel, Y. Du, M. Anwaruzzaman and P. D. McLaughlin (2000) Structure-function relationships of the Rubisco small subunit. In Plant Biology 2000: Final Program and Abstract Supplement. American Society of Plant Physiologists, Rockville, pp. 18 (Abstract).

Spreitzer, R. J., M. G. Esquivel, Y. Du and P. D. McLaughlin (2000) Alanine-scanning mutagenesis of the small subunit of chloroplast Rubisco: An R71A substitution affects $\mathrm{CO}_{2} / \mathrm{O}_{2}$ specificity. In Plant Biology 2000: Final Program and Abstract Supplement. American Society of Plant Physiologists, Rockville, pp. 161 (Abstract).

Du, Y., S. Hong and R. J. Spreitzer (2000) $R b c S$ suppressors enhance the $\mathrm{CO}_{2} / \mathrm{O}_{2}$ specificity and thermal stability of $r b c L$-mutant ribulose-1,5-bisphosphate carboxylase/oxygenase. Proc. Natl. Acad. Sci. USA (submitted).

Spreitzer, R. J., M. G. Esquivel, Y. Du and P. D. McLaughlin (2000) Alanine-scanning mutagenesis of the small subunit of chloroplast ribulose-1,5-bisphosphate carboxylase/oxygenase: Substitution at Arg-71 affects thermal stability and $\mathrm{CO}_{2} / \mathrm{O}_{2}$ specificity. Biochemistry (in preparation).

\section{REFERENCES CITED}

Adam Z (1995) A mutation in the small subunit of ribulose-1,5-bisphosphate carboxylase/ oxygenase that reduces the rate of its incorporation into holoenzyme. Photosynth Res 43:143147

Andersson I (1996) Large structures at high resolution: The $1.6 \AA$ crystal structure of spinach ribulose-1,5-bisphosphate carboxylase/oxygenase complexed with 2-carboxyarabinitol bisphosphate. J Mol Biol 259:160-174

Chen Z, Chastain CJ, Al-Abed SR, Chollet R, Spreitzer RJ (1988) Reduced $\mathrm{CO}_{2} / \mathrm{O}_{2}$ specificity of ribulose-1,5-bisphosphate carboxylase/oxygenase in a temperature-sensitive chloroplast mutant of Chlamydomonas reinhardtii. Proc Natl Acad Sci USA 85:4696-4699 
Chen Z, Green D, Westhoff C, Spreitzer RJ (1990) Nuclear mutation restores the reduced $\mathrm{CO}_{2} / \mathrm{O}_{2}$ specificity of ribulosebisphosphate carboxylase/oxygenase in a temperature-conditional chloroplast mutant of Chlamydomonas reinhardtii. Arch Biochem Biophys 283:60-67

Chen Z, Hong S, Spreitzer RJ (1993) Thermal instability of ribulose-1,5-bisphosphate carboxylase/oxygenase from a temperature-conditional chloroplast mutant of Chlamydomonas reinhardtii. Plant Physiol 101:1189-1194

Chen Z, Spreitzer RJ (1992) How various factors influence the $\mathrm{CO}_{2} / \mathrm{O}_{2}$ specificity of ribulose-1,5bisphosphate carboxylase/oxygenase. Photosynth Res 31:157-164

Cleland WW, Andrews TJ, Gutteridge S, Hartman FC, Lorimer GH (1998) Mechanism of Rubisco: The carbamate as general base. Chem Rev 98:549-561

Eilenberg H, Beer S, Gepstein S, Geva N, Tadmor O, Zilberstein A (1991) Variability in ribulose1,5-bisphosphate carboxylase/oxygenase small subunits and carboxylation activity in fern gametophytes grown under different light spectra. Plant Physiol 95:298-304

Eilenberg H, Hanania U, Stein H, Zilberstein A (1998) Characterization of $r b c S$ genes in the fern Pteris vittata and their photoregulation. Planta 206:204-214

Fitchen JH, Knight S, Andersson I, Branden CI, McIntosh L (1990) Residues in three conserved regions of the small subunit of ribulose-1,5-bisphosphate carboxylase/oxygenase are required for quaternary structure. Proc Natl Acad Sci USA 87:5768-5772

Flachmann R, Bohnert HJ (1992) Replacement of a conserved arginine in the assembly domain of ribulose-1,5-bisphosphate carboxylase/oxygenase small subunit interferes with holoenzyme formation. J Biol Chem 267:10576-10582

Goldschmidt-Clermont M, Rahire M (1986) Sequence, evolution and differential expression of the two genes encoding variant small subunits of ribulose bisphosphate carboxylase/oxygenase in Chlamydomonas reinhardtii. 'J Mol Biol 191:421-432

Gotor C, Hong S, Spreitzer RJ (1994) Temperature-conditional nuclear mutation of Chlamydomonas reinhardtii decreases the $\mathrm{CO}_{2} / \mathrm{O}_{2}$ specificity of chloroplast ribulosebisphosphate carboxylase/oxygenase. Planta 193:313-319

Hartman FC, Harpel MR (1994) Structure, function, regulation, and assembly of D-ribulose-1,5bisphosphate carboxylase/oxygenase. Annu Rev Biochem 63:197-234

Hong S, Spreitzer RJ (1997) Complementing substitutions at the bottom of the barrel influence catalysis and stability of ribulose-bisphosphate carboxylase/oxygenase. J Biol Chem 272:11114-11117

Jordan DB, Ogren WL (1981a) A sensitive assay procedure for simultaneous determination of ribulose-1,5-bisphosphate carboxylase and oxygenase activities. Plant Physiol 67:237-245

Jordan DB, Ogren WL (1981b) Species variation in the specificity of ribulosebisphosphate carboxylase/oxygenase. Nature 291:513-515

Khrebtukova I, Spreitzer RJ (1996) Elimination of the Chlamydomonas gene family that encodes the small subunit of ribulose-1,5-bisphosphate carboxylase/oxygenase. Proc Natl Acad Sci USA 93:13689-13693

Kindle KL (1990) High-frequency nuclear transformation of Chlamydomonas reinhardtii. Proc Natl Acad Sci USA 87:1228-1232

Kleman GL, Horken KM, Tabita FR, Strohl WR (1996) Overproduction of recombinant ribulose1,5-bisphosphate carboxylase/oxygenase from Synechococcus sp. strain PCC6301 in glucosecontrolled high-cell-density fermentations by Escherichia coli K-12. Appl Environ Microbiol 62:3502-3507

Laing WA, Ogren WL, Hageman RH (1974) Regulation of soybean net photosynthetic $\mathrm{CO}_{2}$ fixation by the interaction of $\mathrm{CO}_{2}, \mathrm{O}_{2}$ and ribulose 1,5-diphosphate carboxylase. Plant Physiol 54:678-685

Lee B, Berka RM, Tabita FR (1991) Mutations in the small subunit of cyanobacterial ribulosebisphosphate carboxylase/oxygenase that modulate interactions with large subunits. J Biol Chem 266:7417-7422

Lumbreras V, Stevens DR, Purton S (1998) Efficient foreign gene expression in Chlamydomonas reinhardtii mediated by an endogenous intron. Plant J 14:441-447 
Martin W, Mustafa AZ, Henze K, Schnarrenberger C (1996) Higher-plant chloroplast and cytosolic fructose-1,6-bisphosphatase isoenzymes: Origins via duplication rather than prokaryote-eukaryote divergence. Plant Mol Biol 32:485-491

Newman J, Gutteridge S (1993) The x-ray structure of Synechococcus ribulose bisphosphate carboxylase/oxygenase activated quaternary complex at $2.2 \AA$ resolution. J Biol Chem 268:25876-25886

Read BA, Tabita FR (1992) A hybrid ribulosebisphosphate carboxylase/oxygenase enzyme exhibiting a substantial increase in substrate specificity factor. Biochemistry 31:5553-5559

Read BA, Tabita FR (1994) High substrate specificity factor ribulose bisphosphate carboxylase/oxygenase from eukaryotic marine algae and properties of recombinant cyanobacterial Rubisco containing "algal" residue modifications. Arch Biochem Biophys $312: 210-218$

Schreuder HA, Knight S, Curmi PMG, Andersson I, Cascio D, Sweet RM, Branden CI, Eisenberg D (1993) Crystal structure of activated tobacco rubisco complexed with the reactionintermediate analogue 2-carboxyarabinitol 1,5-bisphosphate. Protein Sci 2:1136-1146

Spreitzer RJ (1993) Genetic dissection of Rubisco structure and function. Annu Rev Plant Physiol Plant Mol Biol 44:411-434

Spreitzer RJ (1998) Genetic engineering of Rubisco. In The Molecular Biology of Chloroplasts and Mitochondria in Chlamydomonas, eds Rochaix $\mathrm{JD}$, Goldschmidt-Clermont M, Merchant S. Kluwer Academic Publishers, Dordrecht, pp 515-527

Spreitzer RJ (1999) Questions about the complexity of chloroplast ribulose-1,5-bisphosphate carboxylase/oxygenase. Photosynth Res 60:29-42

Spreitzer RJ, Chastain CJ (1987) Heteroplasmic suppression of an amber mutation in the Chlamydomonas chloroplast gene that encodes the large subunit of ribulosebisphosphate carboxylase/oxygenase. Curr Genet 11:611-616

Spreitzer RJ, Jordan DB, Ogren WL (1982) Biochemical and genetic analysis of an RuBP carboxylase/oxygenase mutant and revertants of Chlamydomonas reinhardtii. FEBS Lett 148:117-121

Spreitzer RJ, Thow G, Zhu G (1995) Pseudoreversion substitution at large-subunit residue 54 influences the $\mathrm{CO}_{2} / \mathrm{O}_{2}$ specificity of chloroplast ribulose-bisphosphate carboxylase/oxygenase. Plant Physiol 109:681-686

Sugawara H, Yamamoto H, Shibata N, Inoue T, Okada S, Miyake C, Yokota A, Kai Y (1999) Crystal structure of carboxylase reaction-oriented ribulose-1,5-bisphosphate carboxylase/ oxygenase from a thermophilic red alga, Galdieria partita. J Biol Chem 274:15655-15661

Thow G, Zhu G, Spreitzer RJ (1994) Complementing substitutions within loop regions 2 and 3 of the $\alpha / \beta$-barrel active site influence the $\mathrm{CO}_{2} / \mathrm{O}_{2}$ specificity of chloroplast ribulose-1,5bisphosphate carboxylase/oxygenase. Biochemistry 33:5109-5114

Tolbert NE (1997) The $\mathrm{C}_{2}$ oxidative photosynthetic carbon cycle. Annu Rev Plant Physiol Plant Mol Biol 48:1-25

Uemura K, Anwaruzzaman, Miyachi S, Yokota A (1997) Ribulose-1,5-bisphosphate carboxylase/oxygenase from thermophilic red algae with a strong specificity for $\mathrm{CO}_{2}$ fixation. Biochem Biophys Res Commun 233:568-571

Voordouw G, De Vries PA, Van Den Berg WAM, De Clerck EPJ (1987) Site-directed mutagenesis of the small subunit of ribulose-1,5-bisphosphate carboxylase/oxygenase from Anacystis nidulans. Eur J Biochem 163:591-598

Wasmann CC, Ramage RT, Bohnert HJ, Ostrem JA (1989) Identification of an assembly domain in the small subunit of ribulose-1,5-bisphosphate carboxylase. Proc Natl Acad Sci USA 86:1198-1202

Yen A, Haas EJ, Selbo KM, Ross CR, Spreitzer RJ, Stezowski JJ (1998) Preliminary X-ray crystallographic study of wild-type and mutant ribulose-1,5-bisphosphate carboxylase/ oxygenase from Chlamydomonas reinhardtii. Acta Cryst D54:668-670 